\title{
External Reviews in Tenure and Promotions Decisions: How Does the Process Work? How Should It?*
}

\section{Kay Lehman Schlozman, Boston College}

$E_{\mathrm{p}}^{\mathrm{x}}$ xternal reviews in tenure and - promotions cases ... a headache for those who solicit them, a chore for those who write them and, presumably, a source of terror for those who are the subject of them. To assist in making personnel decisions that have significant consequences both for the lives of individuals and for the quality of departments, letters of evaluation are routinely solicited from scholars in other departments. Little is known about whether these letters are used appropriately, whether they contribute to the making of decisions that are fair and professional, or whether the improvement in the quality of decisions is sufficient to justify the investment of time, usually unpaid, by those who provide this assistance.

Responding to concerns expressed by members of the Association -as well as by members of the APSA Council-about the process by which external letters are solicited, written, and used, the Committee on Professional Ethics, Rights and Freedoms and the Committee on Departmental Services conducted a joint study in the spring of 1997. We fielded two surveys: the first a weighted random sample of full professors who are APSA members; the second a weighted random sample of chairs of departmental members of the Association. ${ }^{1}$ The administration of the surveys was not problem-free. ${ }^{2}$ Furthermore, although draft question-

\footnotetext{
Kay Lehman Schlozman chaired the Committee on Professional Ethics, Rights and Freedoms from 1995 through 1997. She is professor of political science at Boston College, where her teaching and research focus on citizen politics in the United States. Her most recent book is Voice and Equality: Civic Voluntarism in American Politics (with Sidney Verba and Henry Brady).
}

naires were scrutinized by many pairs of eyes, in retrospect there are questions that we wish we had included. In addition, we did not survey a third group with a major stake in the process, the candidates for promotion who have recently been, or will soon be, the subjects of these letters. Nonetheless, we learned much that is useful from the results of the surveys-and, just as importantly, from the frequent, lengthy, thoughtful, and sometimes illegible comments that accompanied the questionnaires. $^{3}$

These comments make clear that, with a few exceptions discussed below, there is consensus on the principles that should govern the generation and use of external letters. If the process is to be at once fair and professional as well as respectful of the experience of the candidate under consideration, all who are involved have responsibilities.

The responsibilities of those soliciting external letters include:

- To choose referees with appropriate professional competence and no known biases, either personal or professional, with respect to the candidate being evaluated

- To give referees an opportunity to accept or decline before written materials are sent

- To give referees sufficient time to respond

- To inform referees how their letters will be used and whether there are circumstances under which confidentiality cannot be guaranteed

- To maintain confidentiality of the identity of referees and the contents of letters insofar as legally possible

- To inform referees of the final decision

- To recognize that the process im- poses a professional burden and, therefore, not to request an unnecessarily large number of letters and not to request any letters at all when the nature of the decision does not warrant them.

The responsibilities of external referees include: to make an assessment that is candid and fair, based on professionally relevant criteria and first-hand knowledge; to disclose any personal relationship with the candidate being evaluated; and to respond in a timely fashion.

\section{How Much of a Burden?}

Although there was general agreement as to how the process ought to work, there was less consensus about how the process does work-and considerable doubt that the process is working as it should. One of the concerns that animated the study at the outset-a concern that was echoed frequently in the comments from respondents to the surveys-is that the practice of soliciting outside letters has become so pervasive that it imposes an undue burden on the senior members of the profession who do the writing. The comments accompanying the questionnaires referred to three separate sources of referee inflation: more institutions are requesting outside letters; more letters are being requested for each decision; and letters are being requested for decisions-entry-level and adjunct appointments, renewals of junior appointments, and special increments at the senior level-that did not used to require documentation from the outside.

The data from the surveys cannot be used to confirm or disconfirm the widely held impression of bracket creep with respect to the solicitation of external letters. However, they 
TABLE 1

Solicitation of External Reviews: What Department Chairs Say

\begin{tabular}{|c|c|c|c|c|c|c|}
\hline & \multicolumn{3}{|c|}{ Tenure Cases } & \multicolumn{3}{|c|}{ Promotions Cases } \\
\hline & Ph.D. Dept. & M.A. Dept. & B.A. Dept. & Ph.D. Dept. & M.A. Dept. & B.A. Dept. \\
\hline \multicolumn{7}{|c|}{ Usually request external reviews } \\
\hline All & $91 \%$ & $47 \%$ & $30 \%$ & $90 \%$ & $43 \%$ & $26 \%$ \\
\hline Public institution & $88 \%$ & $42 \%$ & $21 \%$ & $92 \%$ & $39 \%$ & $26 \%$ \\
\hline Private institution & $94 \%$ & $67 \%$ & $33 \%$ & $88 \%$ & $63 \%$ & $26 \%$ \\
\hline \multicolumn{7}{|l|}{ Most recent case } \\
\hline Reviews were requested & $89 \%$ & $48 \%$ & $32 \%$ & $90 \%$ & $47 \%$ & $27 \%$ \\
\hline Mean number requested & 8.6 & 4.1 & 3.8 & 7.8 & 4.6 & 4.0 \\
\hline Mean number received & 6.8 & 3.9 & 3.6 & $\begin{array}{c}6.4 \\
(N=85)\end{array}$ & $\left(N^{4.2}=45\right)$ & $\begin{array}{c}3.5 \\
(N=86)\end{array}$ \\
\hline
\end{tabular}

can document the extent to which the practice is widespread and indicate on whose shoulders the burden of writing letters falls. As shown in Table 1, when making decisions regarding tenure and promotions, Ph.D.-granting departments are extremely likely, and M.A.' and B.A. departments are much less likely, to request letters of evaluation from the outside. Not only are they more likely to solicit outside letters, but $\mathrm{Ph} . \mathrm{D}$. departments ask for more of them. We might surmise that departments in public institutions, which are more likely to be subject to legal strictures regarding procedures and accountability, would also be more likely to request outside letters. Interestingly, once the highest degree awarded by a department is taken into account, the opposite may hold. However, what really matters is whether a department has a Ph.D. program, not whether it is housed within a public or private institution.

The survey of full professors tells the story from the point of view of those being asked to write external letters. In the twelve months before the survey, $61 \%$ of all respondents received at least one request to serve as an external referee. Ninety-two percent of those asked, or $56 \%$ of all respondents, agreed to do so. Taking on this responsibility implied genuine commitment. Letter writers devoted an average of 10.6 hours to the task if the review was for a candidate for tenure, 9.0 hours when the candidate was being considered for promotion. 4
Not unexpectedly, this burden is shared very unevenly among full professors. We had expected that, because they are underrepresented in the upper ranks of the profession, women and non-whites would be asked to write letters more often than white males. As shown in Table 2 , this supposition was correct for women, but, for reasons we do not know, not for minorities. What really matters when it comes to requests for outside letters however, is not ethnicity or sex, but professional visibility. Those in departments with $\mathrm{Ph} . \mathrm{D}$. programs are much more likely to be asked to act as external referees than their counterparts in M.A. and B.A. departments. Taken together, these findings imply a special burden for women in Ph.D.granting departments. In the year preceding the survey, they undertook, on average, one-and-a-third times more external reviews than did their male colleagues in Ph.D. departments, nearly three times more reviews than women in M.A. departments, and more than six times more reviews than men in M.A. departments.

It is interesting to note that there is almost no variation across either demographic groupings or departmental affiliations in the likelihood that the request will be met with assent. In addition, those who denied their most recent request to serve as an outside referee are not shirking their professional responsbilities. On average, they received 4.0 requests over the twelve months preceding the survey, of which they agreed to fulfill 2.8-which is well above the average for the respondents as a whole. Those who said "No" the last time they were asked were given a list of reasons for their decision and asked to check all that applied. Those who indicated that they were too busy may, in fact, be busier than their colleagues, but they are not busier acting as outside referees: they received, on average, 3.1 requests of which they assented to only 0.8 . The small number of respondents who indicated that they have done so many reviews that it was somebody else's turn received, on average, a whopping 9.5 solicitations of which they consented to 1.5 , a figure that is not substantially different from the average of 1.44 fulfilled requests for all respondents.

Consistent with the finding about the extent to which those in Ph.D. departments are much more likely to be asked, data presented in Table 3 indicate that those who are active as researchers or who serve the profession in APSA, in its Organized Sections, or on the editorial boards of journals are more frequently targets of requests for letters. Remarkably high proportions of the respondents to the survey are professionally active in these various capacities. ${ }^{5}$ The small number of respondents who are not active as researchers or who do not take part in disciplinary service are quite unlikely to be asked to serve as external reviewers.

The administrators and department chairs who request these let- 


\section{TABLE 2}

Solicitation of External Reviews: What Full Professors Say

\begin{tabular}{|c|c|c|c|c|}
\hline \multirow[t]{2}{*}{ A } & \multicolumn{2}{|c|}{ Who gets asked? Who says yes? } & & \\
\hline & $\begin{array}{l}\text { Asked within } \\
\text { last } 12 \text { months }\end{array}$ & \multicolumn{3}{|l|}{$\begin{array}{l}\text { Said yes to most } \\
\text { recent request }\end{array}$} \\
\hline All & $61 \%$ & \multicolumn{2}{|l|}{$92 \%$} & $(\mathrm{~N}=467)$ \\
\hline Men & 59 & \multicolumn{2}{|l|}{91} & $(N=335)$ \\
\hline Women & 72 & \multicolumn{2}{|l|}{93} & $(N=113)$ \\
\hline White & 61 & \multicolumn{2}{|l|}{91} & $(N=408)$ \\
\hline Non-white & 50 & \multicolumn{2}{|l|}{95} & $(N=40)$ \\
\hline Ph.D. department & 68 & \multicolumn{2}{|l|}{91} & $(N=352)$ \\
\hline M.A. department & 28 & \multicolumn{2}{|l|}{100} & $(N=54)$ \\
\hline B.A. department & 41 & \multicolumn{2}{|l|}{85} & $(\mathrm{~N}=53)$ \\
\hline \multirow[t]{2}{*}{$B$} & \multicolumn{4}{|c|}{ How many requests to review? How many reviews written? } \\
\hline & $\begin{array}{c}\text { Average number } \\
\text { of requests }\end{array}$ & & \multicolumn{2}{|c|}{$\begin{array}{c}\text { Average number } \\
\text { of reviews }\end{array}$} \\
\hline Men & 1.64 & \multicolumn{3}{|c|}{1.38} \\
\hline Ph.D. department & 1.96 & \multicolumn{3}{|c|}{1.65} \\
\hline M.A. department & .34 & \multicolumn{3}{|c|}{.34} \\
\hline B.A. department & .66 & \multicolumn{3}{|c|}{.59} \\
\hline Women & 2.20 & \multicolumn{3}{|c|}{1.85} \\
\hline Ph.D. department & 2.56 & \multicolumn{3}{|c|}{2.17} \\
\hline M.A. department & .92 & \multicolumn{3}{|c|}{.77} \\
\hline B.A. department & 1.27 & \multicolumn{3}{|c|}{1.00} \\
\hline White & 1.72 & \multicolumn{3}{|c|}{1.45} \\
\hline Ph.D. department & 2.04 & \multicolumn{3}{|c|}{1.72} \\
\hline M.A. department & .41 & \multicolumn{3}{|c|}{.39} \\
\hline B.A. department & .74 & & .64 & \\
\hline Non-white & 1.40 & & 1.17 & \\
\hline Ph.D. department & 1.77 & & 1.47 & \\
\hline M.A. department & .20 & & .20 & \\
\hline B.A. department & .71 & & .57 & \\
\hline
\end{tabular}

ters can take steps to lighten the burden. Most obviously, they can decrease the work load by asking for fewer letters in each case and by asking for no letters at all when the decision being made does not require external documentation. ${ }^{6}$ They can also ease the task by being sure to give reviewers ample time and to provide reviewers with appropriate documents. Table 4 , which presents data about these matters from the perspective of both department chairs and full professors, shows that actual practice usually, though not always, conforms to this standard. There is some discrepancy between what department chairs reported about their most recent requests for letters and what full professors said about the most recent letter they wrote. According to department chairs, reviewers were given an average of 7.2 weeks, and $24 \%$ were given four weeks or less. In contrast, full professors recalled being given an average of 5.6 weeks, and fully $49 \%$ recalled being given four weeks or less. ${ }^{7}$ Even if the accounting of the department chairs is correct, nearly a quarter of external referees are given less than a month to perform the review.

Data about the provision of written materials show a similar pattern. Departments usually, but do not always, send review materials about the candidate and usually, but do not always, establish the referee's willingness to perform the review

\section{TABLE 3}

\section{Requests for External Reviews by Professional Activity}

\begin{tabular}{lcc}
\hline & $\begin{array}{c}\text { Asked within } \\
\text { last 12 months }\end{array}$ & $\begin{array}{c}\text { Average number } \\
\text { of requests }\end{array}$ \\
\hline Scholarly activity in last 3 years & $70 \%$ & 2.12 \\
Published a book & $68 \%$ & 2.03 \\
Published article in refereed journal & $65 \%$ & 1.88 \\
Presented a paper at a major meeting & $7 \%$ & .12 \\
None of these scholarly activities & & $74 \%$ \\
Professional service & $87 \%$ & 2.91 \\
APSA officer or on Council & $90 \%$ & 3.22 \\
APSA Annual Meeting Program Committee & $81 \%$ & 2.48 \\
Any other APSA committee & $81 \%$ & 2.75 \\
Officer of APSA organized section & $79 \%$ & 2.46 \\
Editorial board of major scholarly journal & $25 \%$ & .39 \\
None of these service activities & & $28 \%$ \\
\hline
\end{tabular}


TABLE 4

Facilitating the Review Process

\begin{tabular}{|c|c|c|}
\hline \multirow[t]{2}{*}{ A. } & \multicolumn{2}{|c|}{ Length of Time Given to Complete Review } \\
\hline & $\begin{array}{l}\text { According to } \\
\text { department chairs }\end{array}$ & $\begin{array}{l}\text { According to } \\
\text { full professors }\end{array}$ \\
\hline $1-2$ weeks & $3 \%$ & $9 \%$ \\
\hline $3-4$ weeks & 21 & 40 \\
\hline $5-6$ & 27 & 23 \\
\hline $7-8$ weeks & 24 & 19 \\
\hline $9-10$ weeks & 8 & 3 \\
\hline \multirow[t]{2}{*}{ More than 10 weeks } & 17 & 6 \\
\hline & $\overline{100} \%$ & $100 \%$ \\
\hline \multirow[t]{2}{*}{ Average number of weeks } & 7.2 & 5.6 \\
\hline & \multicolumn{2}{|c|}{$\begin{array}{l}\text { Provision of Review Materials: } \\
\text { Department Chairs Responses }\end{array}$} \\
\hline & $\begin{array}{l}\text { Documents } \\
\text { were sent }\end{array}$ & $\begin{array}{l}\text { Always ask } \\
\text { before sending }\end{array}$ \\
\hline \multicolumn{3}{|l|}{ Most recent tenure decision* } \\
\hline Ph.D. department & $96 \%$ & $88 \%$ \\
\hline M.A. department & 83 & 81 \\
\hline B.A. department & 73 & 96 \\
\hline \multicolumn{3}{|l|}{ Most recent promotion* } \\
\hline Ph.D. department & 93 & 87 \\
\hline M.A. department & 84 & 80 \\
\hline B.A. department & 71 & 94 \\
\hline
\end{tabular}

*Departments requesting external reviews only. before sending documents. As before, the full professors undertaking reviews remember things slightly differently: $23 \%$ of those who per- formed reviews involving documents indicated that documents were sent with the initial request, rather than after they had accepted.

\section{TABLE 5}

\section{Consultation with Candidates in Compiling List of Reviewers}

\begin{tabular}{lcc}
\hline & Tenure & Promotion \\
\hline Names of appropriate reviewers & & \\
Candidate is asked to list & $95 \%$ & $94 \%$ \\
Ph.D. department & 100 & 95 \\
M.A. department & 93 & 100 \\
B.A. department & 100 & 100 \\
(If yes) Names from list selected & 100 & 100 \\
Ph.D. department & 100 & 100 \\
M.A. department & & \\
B.A. department & 60 & 58 \\
Names of inappropriate reviewers & 26 & 21 \\
Candidate is asked to list & 19 & 26 \\
Ph.D. department & & 0 \\
M.A. department & 0 & 0 \\
B.A. department & 0 & 0 \\
\hline (If yes) Names from list selected & 0 & \\
Ph.D. department & & \\
M.A. department & & \\
B.A. department &
\end{tabular}

\section{How Are They Used?}

The comments appended to the questionnaires raised multiple concerns about how the outside letters are actually used in promotion decisions and whether they contribute to making decisions that are just and professionally responsible - concerns that the surveys addressed only very imperfectly. Although it is possible to imagine that departments might use outside letters to devolve to others responsibility for making difficult decisions, it seems that outside letters are much more likely to be used to justify whatever decision the department would have made on its own. The respondents' comments were replete with references to departmental efforts to shore up the reputation of (or, occasionally, to discredit) particular referees or to explain away a letter not congruent to the direction of the departmental decision.

Especially common were references to the construction of lists of referees with a bias toward a preferred outcome. As it happens, the survey showed that many interested parties-including candidates, senior faculty in the department, subcommittees of senior faculty, department chairs, and administrators-have input into the actual selection of reviewers, with practices varying across institutions. As shown in Table 5, candidates for tenure or promotion are almost universally asked for names of appropriate referees, and the final list inevitably includes names from their suggestions. Especially in Ph.D.-granting departments, candidates may be asked if there are reviewers who would be inappropriate. If so, the candidates' wishes are invariably honored. There was no consensus in the comments as to whether obvious allies of the candidate-coauthors, former teachers, or dissertation advisors-should act as referees. On one hand, such referees are obviously not impartial. On the other, these sponsors are often very senior members of the profession who have supervised and worked with many younger scholars and are, therefore, in a position to make informed judgments. Their prejudices 
are likely to be clear-which is not necessarily the case for all reviewers having strong prior dispositions. In short, it is certainly possible to manipulate the choice of referees, either consciously or subconsciously, in order to push the results in a positive or a negative direction. Whether the practice is typical would be difficult to ascertain in a survey.

In terms of their content, comments appended to the questionnaires suggest that external letters tend to be positive. ${ }^{8}$ Several explanations might be adduced for the seeming inclination of referees to pull punches. Possibly, the knowledge that people's careers hang in the balance leads negatively inclined reviewers to moderate their criticisms - or, as suggested in one comment, to decline to participate at all.

Interestingly, fear of being sued was not mentioned in the comments as a reason for the dearth of negative reviews. The absence of a fear of lawsuits, which is perhaps surprising in our litigious environment, is echoed in the results of the survey. As mentioned, respondents who indicated having denied their most recent request were given a list of possible reasons for the decision and invited to check as many as applied. Fear of being sued was the least frequently cited among the alternatives - chosen by only $8 \%$ of those who had denied the recent most request. In contrast, $39 \%$ indicated that they were too busy, $27 \%$ that they did not know the candidate's work well enough, and $23 \%$ that they were not given enough time by the department making the request. Although fear of a lawsuit does not seem to figure significantly in the decision about whether to write a letter, the comments indicate that fear of breaches of confidentiality may be an important piece of the positive bias in outside letters. ${ }^{9}$ The comments contained several anecdotes about the unpleasant fallout that resulted when a negative letter was leaked. While we cannot ascertain the extent to which trepidations with respect to confidentiality result in the tempering of negative comments, it is clear that confidentiality is not infrequently compromised in these matters.

Were we to design the surveys in light of what we now know, we would surely have attempted to probe these issues. In the context of the questions about the solicitation of outside letters in the most recent tenure or promotion decision, the survey for department chairs could have included a battery of questions inquiring into how the external letters were actually used and whether they made any difference. For example, we might have asked for a characterization of the letters, taken together, on a scale ranging from very enthusiastic to very unenthusiastic; about the department's decision in the case; about the extent to which the decision was influenced by the content of the outside letters and would have been different in the absence of letters; and about the final decision made by the university. We might have included items on both questionnaires about the extent to which confidentiality is expected and honored within their home departments and about any experiences with breaches of confidentiality.

\section{Making Comparisons}

As a way of forcing external referees to draw definitive conclusions, those who solicit letters may ask for various kinds of comparisons. All of these forms of forced choice compel an external referee to cut to the chase; however, as noted extensively in the comments accompanying the questionnaires, they raise other issues in the process. The most common request for a bottom-line assessment is to ask outside referees whether the candidate under consideration would be granted tenure in their departments. Outside referees are typically recruited from departments more prestigious than that of the candidate under evaluation. Under the circumstances, a reviewer who has written a sincere and positive appraisal may be faced with the prospect of undermining the case either by admitting that his or her own department, one with higher standards, would not grant the proposed promotion or by making a patronizing statement to the effect of "good enough for your department but not for mine." Moreover, promotion decisions ordinarily entail multiple criteria and considerations beyond the quality and quantity of research-about which the external referee would have no knowledge and cannot be expected to make valid judgments. For these reasons, several respondents suggested that external referees should be instructed to read and evaluate the materials but not to recommend an outcome.

An especially controversial form of comparison involves the pooled list. Outside referees are asked to evaluate several scholars in a particular subfield, usually about a half dozen. Sometimes the outside referee is asked to make explicit comparisons between the person under consideration and others on the list. Sometimes the request is to make comparisons among all the names on the list among which the name of the candidate under consideration is buried without identification.

An unusual version of this technique surfaced in letters circulated recently by a prestigious department. "William Jones" received a letter addressed to "Willard Smith" asking him to evaluate "Thomas Johnson" against a group of scholars among whom was William Jones. ${ }^{10}$ Jones mailed Smith's letter back to the chair of the department making the request with a note saying "Sorrywrong Will." In addition, Jones asked that his name be removed from the list because he is not really in the same subfield as Johnson, the actual candidate for a senior position. Soon Jones received an embarrassed phone call from the department indicating that they would like Jones to act as a referee and that the list for comparison would include Smith's name. Smith, in turn, would receive the correct letter with a list including Jones. Removing Jones's name was impossible because letters had already been circulated to other scholars asking for comparisons between Johnson and Jones, Smith, and the others on the list. Thus, the department had set up a sort of round-robin in which Smith 
was to evaluate Jones and Jones was to evaluate Smith. Meanwhile, Jones, who felt himself inappropriately included in the first place, was concerned that he could hardly compete on an even footing in a field in which he does not publish and would, therefore, naturally be compared unfavorably with others on the list.

The survey of full professors asked explicitly about the practice of asking reviewers to consider a pool of names instead of commenting on a single candidate. Interestingly, a majority $(63 \%)$ of respondents-who are, as we have seen, an extremely professionally active group - were unfamiliar with the practice. Those familiar with the practice were asked an open-ended follow-up question about what they thought of it. This question elicited extensive comment. Less than a quarter of those who replied indicated unambiguous approval-arguing that it compels reviewers to make hard choices. A second group, once again comprising less than a quarter of respondents, expressed mixed views. They acknowledged that the practice requires referees to fish or cut bait but suggested a range of attendant problems. The majority of respondents confined their remarks to unequivocal condemnation of the practice.

Several sorts of objections emerged from the comments. First, concerns were raised about fairness to those on the list who are being compared without their knowledge, much less their permission with the candidate under consideration. That is, scholars who did not ask to be discussed and who have no hope of being offered a position are, unbeknownst to themselves, the subjects of professional evaluation that is often unfavorable. Another set of concerns pertains to the amount of time required to undertake one of these reviews in a professionally responsible manner. Ordinarily, external referees are not sufficiently familiar with the work of all the scholars on the pooled list to make the required comparisons without doing quite a bit of reading. Under the circumstances, the referee may be tempted to cut corners or simply to rely on reputation as a guide.

A final set of issues relates to the construction of the pooled lists. Earlier, I indicated that sets of referees can be put together in such a way as to influence the outcome. The pooled list multiplies the opportunities for stacking the deck. By expanding or contracting the definition of the field, by including senior or emerging scholars, or by affecting the mix of methodological approaches, those assembling the list can have an impact on the results. The construction of the list has consequences not only for the way the candidate under consideration fares but also for what is said about the others in the pool. In the example cited above, William Jones was concerned that being placed on a list of scholars in a subfield in which he does not work would make him the subject of negative evaluations based, not on the quality of his work, but upon the inappropriateness of his qualifications for the particular position. What anyone reading the letters would remember, he surmised, is that he did not stack up very well-not that he should never have been there in the first place.

\section{Should There Be an Honorarium?}

One of the few aspects of the process about which there is genuine disagreement with respect to how things should work is whether service as an external referee should be rewarded with an honorarium. This work is rarely compensated. Discussing their most recent review, only $7 \%$ of respondents said that they had been offered an honorarium. When offered, the payments are modest: The modal honorarium was $\$ 100$; the average was $\$ 127$. The average hourly rate is much closer to what the neighbor's kid is paid for mowing the lawn than to what the plumber is paid for just showing up. Those who reported having been paid an honorarium spent, on average, more time on the review (12 hours) than those who were not paid (9.7 hours). However, it is not clear whether the more important finding is that being paid raised somewhat the number of hours devoted to the task or that those who acted gratis gave as much time as they did.

The question of the appropriateness of an honorarium was raised frequently in the comments accompanying the questionnaires. Opinion was divided almost evenly. On one side, supporters of the practice contend that writing outside letters is time-consuming work undertaken on behalf of another department; therefore, token compensation is appropriate. On the other, opponents argue just as forcefully that serving as an outside reviewer is the professional responsibility of senior members of the discipline; therefore, no compensation should be forthcoming. Clearly, the persuasiveness of both positions suggests that there is no single ethical position on the matter.

\section{Summary}

In conjunction with the comments appended to them, the surveys yielded important insights into the process of soliciting, writing, and using external reviews. The goals of helping faculties to make personnel decisions that are both fair and professionally appropriate while respecting the candidate being evaluated and not placing undue burdens on colleagues outside the department imposes responsibilities on all who take part.

Writing letters for candidates for promotion at other universities does impose substantially, though not uniformly, on senior members of the discipline. Among respondents to the survey, responsibility for acting as an external referee falls disproportionately on women and, especially, the professionally active. Although our surveys cannot document the phenomenon, the comments that accompanied the questionnaires suggest strongly that there has been an escalation in the number of reviews requested. There is a certain irony here. In an era when higher education is under pressure to become more efficient, inflating the number of decisions requiring external reviews and the number of reviews 
needed for each decision makes senior faculty less efficient.

The comments elicited by the questionnaires pointed to several potential problem areas that bear further investigation. One of the most fundamental is whether external reviews even make any difference. In their comments, several respondents expressed a concern that departments use outside letters to buttress whatever case they wish to make, not to guide them in making a determination. One way to predetermine a congenial outcome is to choose the list of reviewers with a particular result in mind. Another concern is the extent to which external referees seem reluctant to make negative judgments-a phenomenon that may reflect a recognition of how high the stakes are for the candidate or a tendency for those who are negatively predisposed to decline to serve as reviewers when asked. The seeming hesitation in delivering bad news may also be related to a fear of breaches of confidentiality. The comments contained anecdotes about the unpleasant consequences that ensued when, in spite of promises to the contrary, candidates got access to reviews.

To force referees to make hard choices, those soliciting external letters sometimes ask for certain kinds of comparisons. Respondents pointed out that making direct comparisons can be problematic when reviewers in more prestigious departments are asked whether they would give tenure to a candidate. One practice that was a subject for considerable criticism is requesting comparisons between a candidate, who may or may not be identified, and several other scholars on a pooled list. The practice is neither widely used nor well known. However, a substantial majority of those who knew about it expressed doubts about whether it is fair to candidates, to reviewers, or to others on the list.

A practice about which there is no consensus is whether it is appropriate to pay an honorarium for service as an outside referee. By and large, this work is performed gratis. Any honorarium is inevitably very small. Nonetheless, opinion is divided evenly over whether those who serve as external reviewers should receive financial compensation for their pains.

\section{What's Next?}

Since decisions about practices surrounding the solicitation, writing, and use of external letters are accountable to no central authority, APSA can obviously do little to affect the way that the process works.
Still, the Ethics Committee is planning two actions based on what has been learned from the survey. First, the Committee is recommending to the APSA Council certain minor changes to the language of the section on "Ethics in Tenure and Promotion" in the Guide to Professional Ethics in Political Science. By and large, this section of the Ethics Guide already reflects the concerns that emerged from the survey. Still, a few alterations would be appropriate. The thrust of the suggestions will be, first, to delete any reference to the appropriateness of honoraria-in light of the utter dissensus on the subject. In addition, the Committee will recommend adding a section on the responsibilities of reviewers "to make an assessment that is candid and fair, based solely on professionally relevant criteria and firsthand knowledge; [ii] to disclose to the department or institution conducting an external review any personal relationship with the candidate being evaluated; and [iii] to honor any deadline to which they have agreed." More important, the Association will investigate ways to publicize the findings of the survey in the hopes that others-in particular, academic administrators who make decisions about external letters and professors in other disciplines-will find its lessions instructive.

\section{Notes}

* I am grateful to Sheilah Mann and Jun Yin of the American Political Science Association for their assistance with the surveys on which this article is based and to the Departmental Services Committee-and, especially, to its chair, Margaret Conway-for jointly sponsoring the surveys.

1. The survey was conducted by Jun Yin, who also analyzed the data. Technical questions about the administration and results of the surveys should be addressed to Dr. Yin (jyin@apsanet.org).

The survey of full professors sampled white males at a ratio of one-third and all others at a ratio of one. The survey of departments contacted chairs of all Ph.D.-granting departments, half of the M.A.-granting departments, and one-third of the B.A. political science and B.A. combined/joint programs. Responses for B.A. political science and B.A. combined/joint programs have been combined in the tables.
In all cases, the data have been appropriately weighted and can be treated as random samples.

2. The surveys, which were originally scheduled for November, were eventually circulated in May, a time when end-of-the-academicyear chores competed for respondents' attention.

The response rate was lower than might have been expected or desired. Moreover, the response rate was uneven with, one suspects, those who have had experience with the solic itation and writing of outside letters-that is, those with something to say on the subjectselectively more likely to respond. Among full professors, those in Ph.D.-granting departments and those with professional visibility were more likely to return the questionnaires, which would have the effect of overstating the average burden imposed by the solicitation of outside letters. Among department chairs, those in B.A.-granting departments hadd markedly lower rates of return. Thus, the already low figure for the proportion of B.A. departments that solicit letters is probably inflated. Response rates were as follows:

\begin{tabular}{lclc} 
& $\begin{array}{c}\text { Full } \\
\text { Professor }\end{array}$ & $\begin{array}{c}\text { Department } \\
\text { Chairs }\end{array}$ \\
\hline Overall & $50 \%$ & Overall & $41 \%$ \\
White male & $53 \%$ & Ph.D. & $67 \%$ \\
White female & $42 \%$ & M.A. & $60 \%$ \\
Minority & $36 \%$ & B.A. & $26 \%$
\end{tabular}

3. The comments appended to the questionnaires bear slight elaboration. Although the survey addressed full professors in their capacity as writers of, and department chairs in their capacity as solicitors of, external reviews, respondents made their comments from the perspectives of many roles. Thus, on the 
basis of their experiences as senior members of departments, full professors raised issues about the use of outside letters in making decisions. Similarly, department chairs mentioned requests to serve as external referees. Respondents to both surveys referred to experiences as deans, as members of university promotions committees, and the like.

4. The stakes are especially high for all concerned when the decision entails the awarding of tenure. Hence, reviewers may take special pains to dispense their responsibilities conscientiously. It is also possible that tenure reviews are more time-consuming because the external reviewer would be less likely to be familiar with the work of an emerging scholar than of a more established member of the profession.

5. Although we cannot measure the extent to which members of Ph.D.-granting departments or research or professionally active faculty are overrepresented among respondents, it is clear that the respondents do not constitute a representative sample of full professors or even of full professors who are members of the Association. Presumably, one source of selection bias would be that those who are asked to write outside letters would be more likely to want to sound off about the process. Moreover, it is also possible that those who act as good citizens-by writing outside letters and by taking on other professional responsibilities-are also more likely to return questionnaires.

6. Of course, department chairs may have little autonomy in deciding which personnel decisions require external documentation.

7. The disparity in the recollections of the two groups of respondents might reflect a tendency for department chairs to begin the mental accounting at the time of the initial inquiry and the full professors at the time of the receipt of written materials-or a natural tendency of each group to give a positive account of their behavior.

8. Although the bias in the direction of the positive was a consistent theme in the comments, several respondents raised the issue of the consternation caused by the occasional letter that is not simply negative, but relentlessly, perhaps even gratuitously, negative.

9. It should be noted that departments differ in the extent to which they are in a position to promise confidentiality to external referees. Departments in public institutions seem to be less likely to be in a position to make promises of confidentiality. In the comments accompanying the questionnaires, one lone respondent argued that candidates for promotion should be able to see a "sanitized" version of the outside letters.

10. These are, of course, pseudonyms. However, the criss-crossing of letters to faculty with similar first names and utterly dissimilar surnames did take place. 